\title{
- Complexo teníase humana - Cisticercose bovina e suína. I - Teníase humana
}

\section{- Human taeniasis - cattle and swine cysticercosis complex. I - Human taeniasis}

\author{
José de Angelis Côrtes -CRMV-SP n 0007 \\ Professor Titular de Zoonoses (aposentado) \\ Faculdade de Medicina Veterinária e Zootecnia da Universidade de São Paulo
}

Rua José Maria Ferreira de Castro, 94 - São Paulo - SP

Fone: (OXX11) 268-3993

Fax: (0XX11) 268-5294

e-mail: deangelis@uol.com.br

\section{RESUMO}

Ao apreciarmos o complexo Teníase Humana - Cisticercose devemos ter em mente a história natural de um agente biológico que, para sua persistência na natureza, necessita, obrigatoriamente, da participação de duas espécies hospedeiras, uma das quais é, necessariamente, a humana. A Taenia solium, por exemplo, em sua forma adulta, hospeda-se, naturalmente, no intestino delgado do ser humano e, em sua forma larvar, o Cysticercus cellulosae, no tecido muscular de suínos. O ser humano é, também, o hospedeiro obrigatório da forma adulta da Taenia saginata, enquanto que a correspondente forma larvar, o Cysticercus bovis, infecta o tecido muscular de bovinos. Neste primeiro artigo trataremos do processo doença intitulado Teníase Humana, salientando: a importância desta espécie, única hospedeira da forma adulta das duas tênias, bem como seu papel na transmissão da cisticercose; o mecanismo envolvido em sua infestação pela ingestão de cisticercos vi áveis com carne crua ou mal cozida; a patologia (lesões e sintomas) discreta ressaltando a importância da observação, pelo paciente, da presença de proglotes nas fezes; o significado da identificação da espécie da tênia por ocasião do tratamento do paciente e a essencialidade das ações preventivas globais, buscando romper a cadeia epidemiológica deste agente em seus diferentes pontos críticos.

Palavras chave: complexo teníase cisticercose, teníase humana, Taenia solium, Taenia saginata, forma adulta, forma larvar.

\section{TENÍASE HUMANA}

\section{Caracterização}

$\underline{\mathrm{S}}$ ob esta designação apreciamos a condição patológica decorrente da infestação humana pela fase adulta da Taenia solium ou da Taenia saginata.

A Teníase é conhecida desde os tempos pré-históricos. Referências a essas tênias são encontradas nos Papiros EBERS, na literatura indiana e chinesa, nos registros dos autores greco-romanos, bizantinos e árabes. Todavia, a associação entre o parasita e sua forma larvar, em bovinos, somente foi estabelecida em 1861 por Levckart, fazendo bezerros ingerir proglotes grávidos de $\mathrm{Ta}$ - enia saginata e obtendo sua correspondente forma vesicular. Oito anos mais tarde, Oliver, empregando um procedimento reverso, conseguiu transmitir a Taenia saginata ao ser humano, pela ingestão do cisticerco de origem bovina (PAWLOWSKY e SCHULTZ, 1972).

\section{Distribuição Geográfica e Prevalência}

A afecção humana decorrente da infestação pela forma adulta da Taenia solium ou da Taenia saginata é cosmopolita, sendo comum em todas as partes do mundo onde se consome carne de porco ou de boi crua ou mal cozida.

Embora apresentando uma distribuição universal, os registros de prevalência da teníase humana são pouco 
Figura1: Representação esquemática da Taenia solium (Adaptado de OLSEN, O.W., 1974)

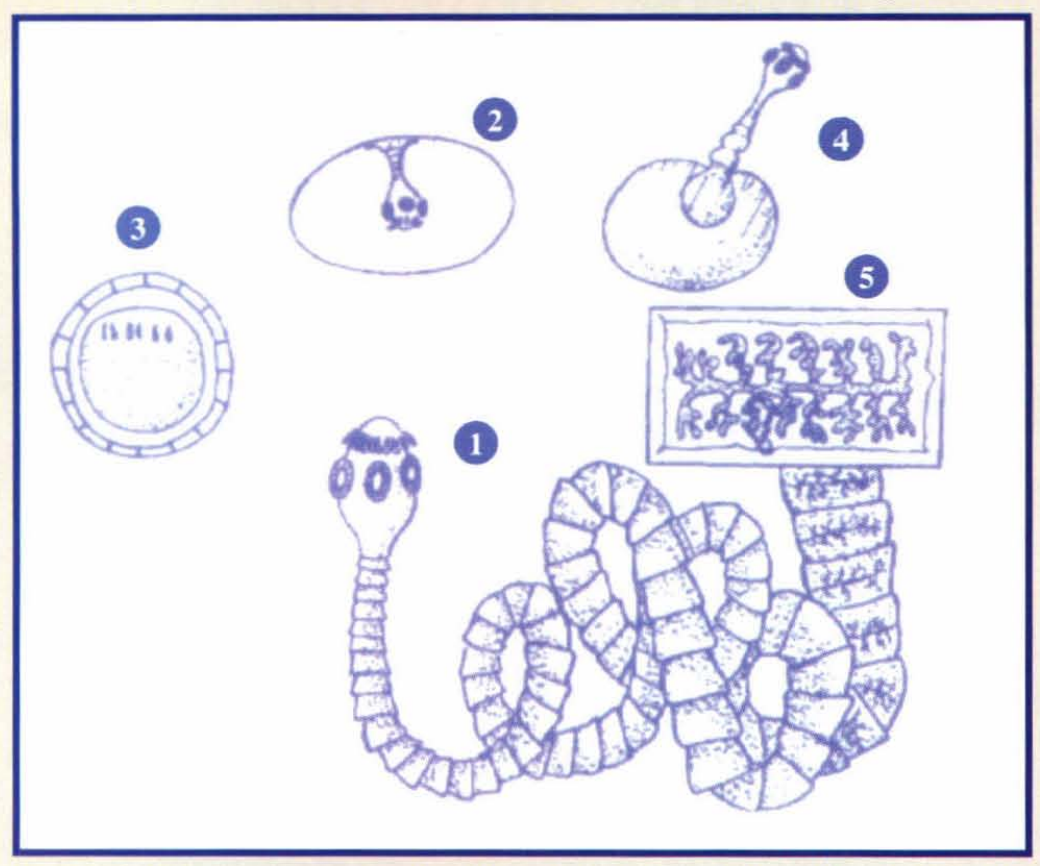

1) Taenia solium - escolex com ventosas e coroa de ganchos.

2) Ovo com sua estrutura interna e envoltório externo.

3) Cisticerco invaginado.

4) Cisticerco desinvaginado.

5) Último segmento com detalhes de suas ramificações uterinas e em certas partes da África, devido ao hábito de consumir carne crua em pratos tradicionais como o quibe e outros. Na América Latina é freqüente naqueles países onde o consumo de carne bovina é maior. A julgar-se pela elevação das taxas de detecção de lesões nas carcaças de bovinos abatidos em matadouros parece evidente que a prevalência desta teníase vem sofrendo uma tendência crescente nas regiões onde ocorre.

Em 1947, Stoll calculou que o número de pessoas parasitadas, em todo o mundo, pela Taenia saginata era de 39 milhões e pela Taenia solium, de $2,5 \mathrm{mi}-$ lhões. As investigações realizadas, desde então, têm revelado a existência de muitos focos com altas taxas de infestação em áreas anteriormente livres ou com prevalência reduzida. Além disso, a densidade populacional, tanto humana como animal, tem sofrido um intenso crescimento (ABDUSSALM, 1975).

\section{Importância econômica e social}

consistentes uma vez que são representados, usualmente, por estudos fragmentários, a maioria dos quais realizados no curso de duas a três décadas. Com exceção dos dados obtidos em inquéritos massais realizados na Rússia e Polônia, a maior parte da informação baseia-se em informes isolados sobre o estudo de certos segmentos da população, tais como escolares, pacientes hospitalizados, presidiários, etc. (ABDUSSALM, 1975)

Na Rússia a prevalência da teníase humana baixou de 0,6\%, em 1950, para 0,075\% em 1966 (BESSONOV, 1974; ALUJA et al., 1987; ACHA e SZYFRES, 1996). Tal sucesso deveu-se a um intensivo programa de tratamento massal da população humana nas zonas endêmicas.

A ocorrência da Taenia solium, por exemplo, parece ser maior na América Latina, na África e nos países não-muçulmanos do Sudeste asiático. Em contrapartida, são livres da doença os países de população muçulmana e israelita, em virtude da proibição religiosa do consumo de carne suína (EUZEBY, 1966). Sua ocorrência tem assumido uma tendência decrescente à medida que avançam os procedimentos tecnológicos na produção pecuária suína.

Por outro lado, a Taenia saginata apresenta uma ocorrência particularmente importante no Oriente Médio
A importância desta zoonose está relacionada a dois aspectos principais:

1. doença na população humana;

2. papel que o homem parasitado desempenha como fonte de infecção para a cisticercose animal e humana (ACHA e SZYFRES, 1996).

Os custos médicos decorrentes da teníase humana são difíceis de ser estabelecidos. A infestação raramente é fatal, a menos que o verme assuma uma localização errática. A sintomatologia é muito variada e, provavelmente, causa uma redução da produtividade dos indivíduos afetados (ABDUSSALM, 1975).

\section{Etiologia}

A etiologia da teníase humana envolve a forma adulta da Taenia solium e/ou da Taenia saginata, parasitas que pertencem à classe Cestoidea, ordem Cyclophyllidea e família Taeniidae. São vermes achatados e em forma de fita apresentando pequenas diferenças morfológicas entre si (REY, 1991).

A Taenia solium (Figura 1), mede normalmente 1,5 a 4 metros, podendo alcançar até 8 metros de com- 
primento; sua cabeça (escólex) possui 4 ventosas e um "rostelo" guarnecido por duas fileiras de ganchos ou acúleos, daí a denominação de "tênia armada". O corpo é formado por uma cadeia de segmentos conhecidos como proglotes que constituem verdadeiras unidades reprodutoras independentes, em número de 700 a 900 e, quando grávidos, podem conter em seu interior de 30 a 50 mil ovos. As proglotes grávidas apresentam ramificações uterinas pouco numerosas ( 7 a 16 de cada lado da haste central) com distribuição irregular e aspecto dendrítico (ALUJA et al., 1987; DUMAS et al., 1989; REY, 1991). Diariamente um indivíduo parasitado elimina pequenos segmentos da cadeia com cerca de 5 proglotes que ganham o meio externo misturados com as fezes.

\section{A Taenia saginata (Fi-}

gura 2), com características muito similares à anterior, é bem mais alongada, medindo 4 a 12 metros, chegando mesmo ao extremo de 25 metros. Seu escólex (cabeça) é desprovido da coroa de ganchos (acúleos) sendo, por isso, denominada de tênia inerme ou desarmada. O estróbilo é constituído por 1.000 a 2.000 proglotes e estas, quando grávidas apresentam ramificações mais numerosas ( 15 a 30 de cada lado) com aspecto dicotômico, contendo, cada uma, em seu interior, cerca de 80.000 ovos. Desta cadeia de proglotes desprendem-se, diariamente, ao redor de 8 a 9 proglotes, de sorte que um indivíduo parasitado contribui com aproximadamente 700.000 ovos/dia para a contaminação ambiental (ALUJA et al., 1987; REY, 1991).

Dos ovos de tênia 50\% aproximadamente são maduros e infectantes (ABDUSSALM, 1975; ALUJA et al., 1987). Usualmente tais ovos, juntamente com os imaturos, são expelidos, no interior das proglotes, com as fezes do hospedeiro. Os imaturos virão a amadurecer no meio externo e permanecer viáveis por longo tempo (ALUJA et al., 1987).

Esses parasitas apresentam uma expressiva longevidade, podendo apresentar uma sobrevida de até 25 anos (PATAK, 1989; REY, 1991) na Taenia so- lium e de 30 anos no caso da Taenia saginata (REY, 1991).

\section{Hospedeiros}

O homem é o único hospedeiro da forma adulta da Taenia solium e da Taenia saginata. Não existem provas concludentes que outros mamíferos possam ser hospedeiros naturais da forma adulta destes parasitas (ABDUSSALM, 1975). Contudo, em condições experimentais tem sido registrado seu desenvolvimento, ainda que parcial, em macacos (gibbon e babbon); no hamster dourado e no cão (HERBERT e OBERG, 1974; ACHA e SZYFRES, 1996).

\section{Mecanismos de infestação Fontes de infecção}

O único mecanismo pelo qual o homem pode contrair a teníase, pela Taenia solium ou pela Taenia saginata é representado pela ingestão do Cysticercus cellulosae ou Cysticercus bovis com carne suína ou bovina crua ou mal cozida (ABDUSSALM, 1975; ALUJA et al., 1987; REY, 1991; VILLA, 1995; ACHA e SZYFRES, 1996). Sendo os suínos e javalis (ABDUS- 
Figura 3: Representação esquemática do mecanismo de infestação humana pela Taenia saginata e pela Taenia solium (Adaptada de OLSEN, O.W., 1974).

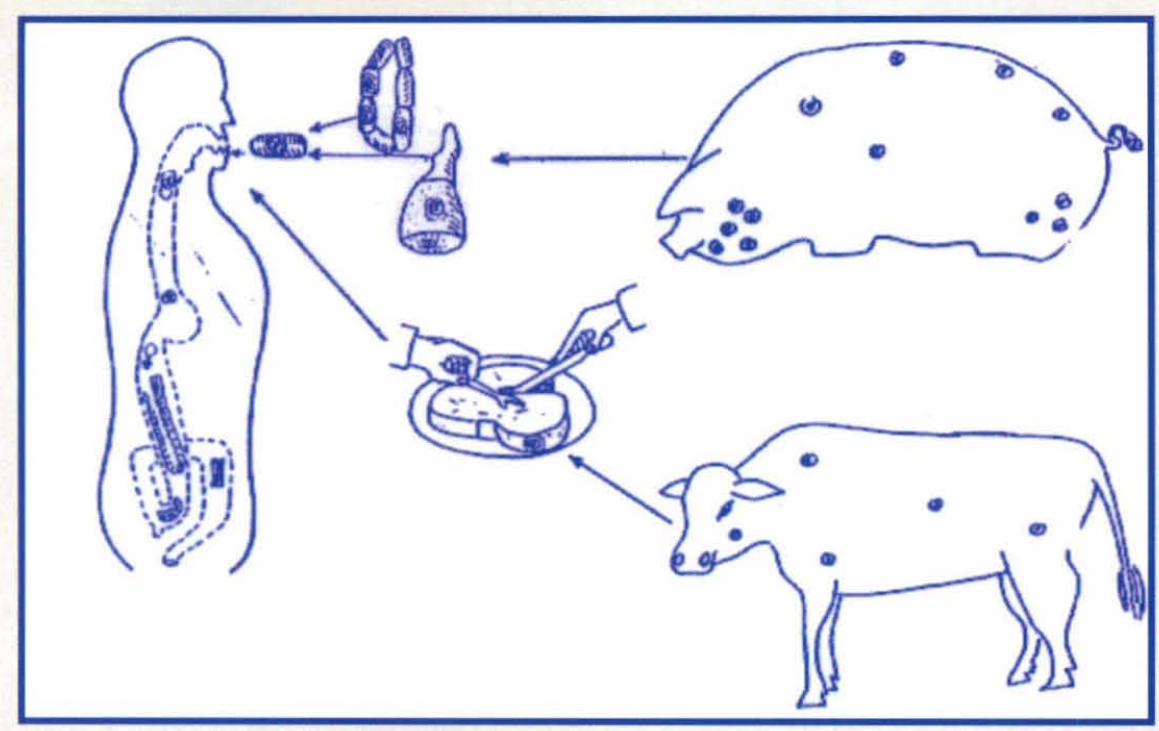

Fonte: Comum. cient. Fac. Med. Vet. Zootec.Univ. S. Paulo, v.8, n. 2, p. 231-41, 1984. com carne suína ou bovina, crua ou mal cozida. Aparentemente, o cisticerco não sofre qualquer alteração em nível do estômago; todavia, ao atingir a altura do intestino delgado, seu escólex desinvagina-se pela ação da bile e dos sucos digestivos e fixa-se à mucosa do órgão, graças a ventosas e/ou acúleos, transformando-se na tênia adulta em aproximadamente 60 a 70 dias, quando os pacientes começam a evacuar as primeiras proglotes.

Uma vez no intestino, a tênia exerce uma ação irritativotraumática sobre a parede do órgão que resulta em uma ligeira reação inflamatória subaguda em muitos casos.
SALM, 1975) e os bovinos os hospedeiros naturais mais importantes desses agentes e, por conseguinte, os principais responsáveis pela transmissão da teníase ao homem (Figura 3), parece factível considerar-se este "elo" da cadeia de transmissão, como o mais significativo ponto crítico de risco para a infestação do homem pela forma adulta desses parasitas.

A despeito de indicações de que cães, gatos e macacos possam também infectar-se com o Cysticercus cellulosae, a participação desses hospedeiros como fonte de infecção somente poderia ocorrer naqueles países onde sua carne fosse aproveitada para o consumo humano (HERBERT e OBERG, 1974). Do mesmo modo, embora o Cysticercus bovis possa ocorrer em certos ruminantes, o papel de tais espécies na transmissão da teníase humana tem sido considerado irrelevante, só ocorrendo em condições muito excepcionais.

Relativamente à espécie humana, conquanto o Cysticercus cellulosae possa evoluir em seus tecidos, acarretando severos transtornos, esse hospedeiro não contribui, naturalmente, para a perpetuação do parasita na natureza, caracterizando-se como hospedeiro terminal, salvo em caso de regiões onde se pratica, eventualmente, o canibalismo.

\section{Patogenia}

Como vimos, o homem contrai usualmente a teníase ao ingerir Cysticercus cellulosae ou Cysticercus bovis

\section{Sintomas}

A teníase pode apresentar-se sob a forma clínica ou sub-clínica, imperceptível, salvo pela evacuação de proglotes, manifestada apenas por um desconforto.

Todas as informações disponíveis sugerem que o quadro clínico do parasitismo pela Taenia solium seja em tudo similar ao descrito por PAWLOWSKY e SCHULTZ (1972) para a Taenia saginata. Para eles o sintoma mais frequiente e característico é a descarga de proglotes $(98,3 \%)$ que, no caso da Taenia solium pode passar despercebido pelo paciente. Além deste, aproximadamente $3 \mathrm{em}$ cada 4 pacientes com teníase experimentam um ou mais dos sintomas seguintes: dores abdominais $35,6 \%$; náuseas $34,4 \%$; debilidade $24,8 \%$; perda de peso $21,0 \%$; aumento do apetite $17,0 \%$; dores de cabeça $15,5 \%$; constipação $9,4 \%$; mareio (tontura) $8,2 \%$; diarréia $5,9 \%$; prurido anal $4,5 \%$ e excitação $3,4 \%$ (PAWLOWSKY e SCHULTZ, 1972).

Usualmente o portador desta parasitose alberga um único exemplar, daí o nome popular de SOLITÁRIA; todavia, a infestação múltipla tem sido verificada por vários autores. Tem-se admitido que o primeiro verme instalado desenvolveria um estado imunitário que impediria o desenvolvimento de tênias da mesma espécie mas não de espécies diferentes (REY, 1991).

A presença da Taenia saginata acarreta, usualmente, uma maior frequiência de agravos à mucosa duodenal, alterações de motricidade e das secreções digesti- 


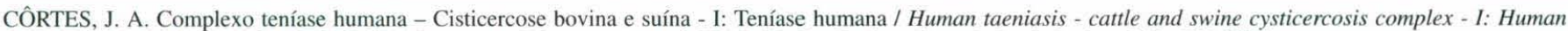
taeniasis. / Rev. educ. contin. CRMV-SP / Continuous Education Journal CRMV-SP, São Paulo, volume 3, fascículo 1, p. 055 - 061 , 2000.

vas. Ocasionalmente podem ser constatadas localizações erráticas, como penetração de proglotes no apêndice, provocando apendicite ou, em casos de regurgitamento, proglotes podem ser aspiradas causando obstrução brônquica (REY, 1991).

No caso da Taenia solium o maior significado advém da possibilidade de ser o homem também hospedeiro da correspondente forma larvar, a cisticercose.

\section{Diagnóstico}

A sintomatologia decorrente do parasitismo por tênias adultas é tão pouco característica que o diagnóstico clínico depende sempre de confirmação laboratorial. As técnicas ou meios biológicos utilizados são: fixação de complemento, reação de precipitação, hemaglutinação, imunofluorescência, eosinofilia, síndrome liquórica (PESSOA, 1982).

Da maior importância é a participação do próprio paciente ao identificar a presença de proglotes em suas fezes.

Os anéis da Taenia solium são, usualmente, eliminados com as fezes, passivamente, em grupos de 3 a 6, enquanto que os da Taenia saginata abandonam o hospedeiro um a um, isoladamente, de sorte que poderão passar despercebidos na massa fecal. Todavia, graças a sua forte musculatura e atividade motora, conseguem sair ativamente, forçando a passagem pelo orifício anal em qualquer oportunidade, sendo encontrados na roupa de cama ou roupa íntima, o que chama a atenção do próprio paciente ou de terceiros (REY, 1991).

Algumas evidências epidemiológicas como: a procedência do paciente, seus hábitos alimentares, existência da doença na família ou grupo social, etc., podem ajudar no diagnóstico presuntivo. Sem dúvida alguma, a observação pelo paciente, da presença de proglotes nas fezes e a correspondente coleta de material para exame laboratorial, facilitam sobejamente o diagnóstico. Entre as técnicas utilizadas para o exame de fezes, destacam-se: pesquisa de proglotes (tamização da matéria fecal), pesquisa de ovos com a fita adesiva e pesquisa de ovos nas fezes (REY, 1991).

A primeira baseia-se no conhecimento de que cada parasita libera, diariamente, vários anéis. A peneiragem da evacuação total das 24 horas vai demonstrar a presença dos proglotes da tênia.

O exame microscópico de tais proglotes possibilita a observação do útero e de suas correspondentes ramificações.

A técnica da fita adesiva fundamenta-se no fato de que, ao transpor o esfíncter anal, as proglotes comprimidas libertam ovos que ficarão presos na região perianal. Ao aplicar-se, nesta região, a fita adesiva transparente os ovos eventualmente presentes irão a ela aderir-se e serão revelados posteriormente no exame laboratorial (REY, 1991).

Para a pesquisa de ovos nas fezes convém considerar que estes vermes não ovipõem e, como tal, apenas rara e ocasionalmente, os ovos poderão ser encontrados neste material.

Morfologicamente os ovos de Taenia solium são praticamente indiferenciáveis dos da Taenia saginata, mas tal distinção pode ser conseguida pela reação em cadeia da polimerase (PCR) (OIE, 1996).

O diagnóstico diferencial da espécie de tênia é realizado usualmente pelo exame microscópico de proglotes maduras tomando-se como base o número de ramos uterinos laterais. Tais ramificações são pouco numerosas na Taenia solium (7 a 16 de cada lado) e apresentam-se muito irregulares com aspecto dendrítico, ao passo que na Taenia saginata elas são do tipo dicotômico e em número de 15 a 30 a cada lado (REY,1991; ACHA e SZYFRES, 1996; OIE, 1996).

Os testes de diagnóstico imunológico, hemaglutinação indireta e de imunofluorescência indireta podem ser úteis mas seu valor é ainda limitado.

\section{Tratamento}

O tratamento da teníase deve ser precedido da necessária identificação da espécie de tênia que acomete o paciente, não apenas visando a escolha da medicação mais adequada, mas também para orientar a conduta a ser adotada pelo doente visando evitar riscos futuros em caso de infecção por Taenia solium (REY, 1991).

A escolha de uma droga depende de dois fatores fundamentais: a eficiência e a inocuidade.

A Niclosamida tem se constituído na droga de escolha para o tratamento das teníases do homem por apresentar um elevado nível de segurança, traduzida por uma taxa de cura da ordem de $90 \%$ e efeitos colaterais quase inexistentes.

Igualmente eficiente, isento de riscos e efeitos colaterais, figura o praziquantel, cuja utilização encontra limitações nos casos de teníase (Taenia solium) em pacientes portadores de cisticercose (ALUJA et al., 1987; CAMACHO et al., 1991; REY, 1991). Outras drogas como o mebendazol e a paramomicina têm sido indicadas como terapêutica alternativa (REY, 1991).

No tratamento das teníases alguns aspectos devem merecer cuidadosa atenção:

a) relativamente ao tratamento do parasitismo por Taenia solium, atentar para o risco decorrente da 
ocorrência de náuseas e vômitos durante o procedimento terapêutico. Em tais situações, ovos do parasita podem, por um processo de retro-peristaltismo, alcançar o estômago e, em seguida, retornar ao intestino, resultando no estabelecimento de uma cisticercose no mesmo hospedeiro (auto-infecção endógena). Os cuidados de higiene também não devem ser negligenciados a fim de evitar a eventual transferência de ovos do ânus à boca do paciente (auto-infecção exógena) (ALUJA et al., 1987; REY, 1991), ou a contaminação ambiental, uma vez que os medicamentos utilizados não são, usualmente, ovicidas;

b) o controle da cura: com os medicamentos atuais, os vermes são eliminados desintegrados e quase sempre é possível a identificação dos escoleces nas evacuações após o tratamento. Resta apenas esperar, se houver fracasso na terapêutica, o reinício das eliminações de anéis, o que ocorrerá em 2 a 3 meses (REY, 1991).

\section{Profilaxia}

A profilaxia da teníase humana apóia-se em um conjunto de medidas que visa impedir o parasitismo humano pela forma adulta da Taenia solium e, com isso, bloquear o ciclo do parasita na natureza.

Em essência, a ação preventiva apóia-se em duas linhas básicas, a saber:

a) medidas indiretas com o objetivo de impedir que os suínos adquiram a cisticercose;

b) medidas diretas que visam, fundamentalmente, proteger o homem contra a infestação, pela forma adulta desse parasita, decorrente da ingestão de cisticercos viáveis, com carne suína ou bovina, crua ou mal cozida. Entre as alternativas de atuação figuram:

\section{Sobre as fontes de infecção}

$\mathrm{Na}$ atualidade não se dispõe de recursos, de comprovada eficiência e viabilidade econômica, para o diagnóstico e o tratamento da cisticercose animal "in vivo".

\section{Sobre as vias de transmissão}

Inspeção sanitária da carne dos animais abatidos: esta é a medida direta de maior significado na prevenção da teníase humana. Ela consiste no exame das carcaças dos animais abatidos para o consumo humano, com o propósito de assegurar a qualidade sanitária do alimento, ou seja, reduzir o risco de transmissão da teníase pela ingestão de carne suína. Ela contempla o diagnóstico, o destino e o tratamento das carcaças parasitadas.

- Diagnóstico: os recursos diagnósticos disponíveis dependem do exame macroscópico apoiado rotineiramente em localizações classicamente denominadas "preferenciais", tais como: coração, músculos da mas- tigação, língua, diafragma e seus pilares, fígado, pulmões, cérebro e paletas entre outras (REY, 1991; VILLA, 1995). Alguns admitem que tais procedimentos são inadequados e podem deixar escapar parte significativa das carcaças parasitadas, particularmente nos casos de infecções leves, comuns na cisticercose bovina (ABDUSSALM, 1975), porém pouco usuais entre os suínos.

- Destino (em função da Regulamentação da Inspeção Industrial e Sanitária de Produtos de Origem Animal - RIISPOA): outro aspecto interferente refere-se ao destino da carne parasitada. Face à impossibilidade econômica do descarte de todas as carcaças parasitadas, os critérios de destino fundamentam-se no grau de parasitismo do animal. As carcaças com 1 cisticerco calcificado podem ser destinadas à salsicharia; com poucos cisticercos vivos, ao aproveitamento condicional pela salga, a seco ou à fabricação de banha; infecção intensa, à total rejeição (REY, 1991).

- Tratamento: as carcaças parasitadas são tratadas, usualmente, pelo frio, pelo calor ou pelo sal. O congelamento da carne a $-15^{\circ} \mathrm{C}$, durante 6 dias, inativa efetivamente os cisticercos. Do mesmo modo, seu aquecimento à temperatura superior a $55^{\circ} \mathrm{C}$ é efetivo desde que estes níveis térmicos atinjam o interior da massa muscular (REY, 1991). Para EUZEBY (1966), a salga só é eficiente para a destruição do cisticerco quando: máximo;

a) atua em fragmentos de dois a três quilos no

b) são utilizadas salmouras concentradas com título de pelo menos 25 graus Baumé;

c) sua atuação é levada a efeito por um período mínimo de três semanas. Nos países tropicais, a salga a seco (50 gramas de sal por quilo de carne), associada à dessecação (perda de 30 a $40 \%$ de água), assegura a destruição dos cisticercos nos músculos.

3. Sobre a comunidade: Certos pontos básicos de orientação sanitária devem ser abordados para que se consiga sucesso em um programa de profilaxia da teníase, entre os quais figuram a orientação da população para:

- somente utilizar carne suína ou bovina, como alimento, quando esta tenha sido devidamente inspecionada e devidamente cozida;

- abolir o costume de consumir carne suína ou bovina crua ou mal cozida;

- destinar, de forma adequada, os excretas humanos e adotar os demais hábitos de higiene com o intuito de impedir, diretamente, a ocorrência da cisticercose nos animais e, indiretamente, a teníase no homem;

- reconhecer quando se encontram acometidas de teníase, pela identificação de proglotes nas fezes. 


\section{SUMMARY}

A global approach of the Human Taeniasis-Cysticercosis Complex must take into account the natural history of a biological agent that requires the interactive relationship with two vertebrate species for its persistence, one of them being necessarily the human species. In fact, man is the obligatory host of both Taenia solium and Taenia saginata adult stages, while pig and cattle are the larval stage natural hosts (Cysticercus cellulosae and Cysticercus bovis respectively). The human taeniasis disease process is presented in the first part of this review, emphasizing some relevant aspects such as man's importance as the only natural host able to harbor both $T$. solium and $T$. saginata adult forms and his role in the cysticercosis transmission mechanism; the human infestation mechanism by eating viable cysticerci with raw and/or undercooked meat; the role of animal species as taeniasis source of infection; the mild pathology (lesions and symptoms) stressing the importance of the patient's observation of faeces as to the presence of proglottis; the significance of identifying the taenia species when the patient is treated, as well as the importance of global preventive actions in disrupting the epidemiological chain of this agent in different critical points.

Key words: taeniasis-cysticercosis complex, human taeniasis, Taenia solium, Taenia saginata, adult stages, larval stages.

\section{REFERÊNCIAS BIBLIOGRÁFICAS}

01 - ABDUSSALM, M. El problema de la teniasis-cisticercosis. Washington: Organizacion Panamericana de la Salud, 1975. (Publicacion cientifica, 295).

02 - ACHA, P.N.; SZYFRES, B. Zoonosis y enfermedades transmissibles comunes al hombre y a los animales. 2. ed. Washington: Organizacion Panamericana de la Salud, 1996. (Publicacion cientifica, n. 505).

03 - ALUJA, A S.; ESCOBEDO, A E.F.; LACLETTE, A F.J.P.; MADRAZZO, C.L.I.; WILLMS, V.V.K. Cisticercosis. Mexico: Biblioteca de la Salud. Instituto Nacional de Salud Publica; 1987.

04 - BESSONOV, A S. Perspectives on the erradication of several helminthozoonotic diseases in the URSS. In: SOULSBY, E.J.L. Parasitic zoonoses. Clinical and experimental studies. New York: Academic Press, 1974. p. 179-86.

05 - CAMACHO, S.P.D.; RUIZ, A.C.; PERAZA, V.S.; RAMOS, M.L.Z.; MEDINA, M.F.; LOZANO, R.; WILLMS, K.; DIAZ-CAMACHO, S.P. Epidemiological study and control of Taenia solium infections with praziquantel in a rural village of Mexico. American Journal of Tropical Medicina and Hygiene, v.45, n. 4, p. 522-31, 1991.

06 - DUMAS, M.; GRUNITZKY, E.; DENIAU, M.; DABIS, F.; BOUTEILLE, B.; BELO, M.; PESTRE-ALEXANDRE, M.; CATANZANO, G. DARDE, M. L.; D'ALMEIDA, M. Epidemiological study of neuro-cysticercosis in northern Togo (West Africa). Acta Leidensai, v. 57, n. 2, 191-96, 1989.
07 - EUZEBY, J. Les maladies vermineuses des animaux domestiques et leurs incidences sur la pathologie humaine. Paris: Vigot Freres, 1966.

08 - HERBERT, V.; OBERG, C. Cysticercosis in pigs due to infection with Taenia solium LINNAEUS, 1758. In: SOULSBY, E.J.L. Parasitic zoonoses. Clinical and experimental studies. New York: Academic Press, 1974.

09 - OIE-OFFICE INTERNATIONAL DES EPIZOOTIES. Manual of standards for diagnostic test and vaccines. Lists A and $B$ diseases of mammals, birds and bees. 3. ed, Paris: OIE, 1996

10 - OLSEN, O.W. Animal parasites: their life cicles and ecology. 3. ed. Baltimore: University Park Press, 1974. p.351-8.

11 - PATAK, K.M.L. Cysticercosis in India. A review and update of cysticercosis caused by Taenia solium. Zoonosis Revista International, Brasilia, v. 1, n. 2, p. 21-9, 1989.

12 - PAWLOWSKY, Z.; SCHULTZ, M.G. Taeniasis and Cysticercosis (Taenia saginata). Advances in Parasitology. n.10, p. 269-343, 1972.

13 - PESSOA, S.B.; MARTINS, A.V. Parasitologia médica, 11 ed., Rio de Janeiro: Guanabara Koogan, p. 501-19, 1982.

14 - REY, L. Parasitologia. Parasitos e doenças parasitárias do homem nas Américas e na África. Rio de Janeiro: Guanabara Koogan, 1991.

15 - VILLA, M.F.G. Epidemiological situation of complicated taeniasis/cysticercosis as public health problem of Brazil. Higiene Alimentar, v. 9, n. 36, p. 8-11, 1995. 